\title{
Diagnostic accuracy and reliability of retinal pathology using the Forus 3nethra fundus camera compared to ultra wide-field imaging
}

\author{
Dana Y. Darwish ${ }^{1} \cdot$ Samir N. Patel ${ }^{2} \cdot$ Yan Gao $\mathbb{1}^{3} \cdot$ Pooja Bhat ${ }^{1} \cdot$ Felix Y. Chau ${ }^{1} \cdot$ Jennifer I. Lim ${ }^{1} \cdot$ Judy E. Kim $^{4}$. \\ Jogin Jose $^{1} \cdot$ Karyn E. Jonas $^{1} \cdot$ R. V. Paul Chan ${ }^{1,5} \cdot$ Supriya D. Mehta ${ }^{3} \cdot$ Ann-Marie Lobo $^{1}$
}

Received: 24 September 2018 / Revised: 18 December 2018 / Accepted: 2 January 2019 / Published online: 24 January 2019

(c) The Royal College of Ophthalmologists 2019

RVPC is a member of the Scientific Advisory Board for Visunex Medical Systems (Fremont, CA). No conflicting relationship exists for any of the other authors.

Telemedicine programs provide an affordable method to screen for eye conditions in resource limited settings, but are impeded by costs of expensive imaging systems.

We performed a prospective pilot study at the Illinois Eye and Ear Infirmary to evaluate the accuracy and reliability of detecting retinal pathology using the Forus 3nethra (Forus) fundus camera compared to ultra wide-field (UWF) imaging with Optos 200Tx. Images were compared against clinical diagnosis by ophthalmoscopy as the reference standard.

Patients underwent mydriatic imaging with Optos and Forus. Three double-blinded graders independently evaluated Forus (45 degree, central, nasal, superior, and inferior views) and Optos (200 degree) images (Fig. 1) for the presence or absence of pathology, image clarity, and specific clinical diagnoses of diabetic retinopathy, choroidal lesions, or uveitis. Graders were asked to choose a diagnosis, rate confidence level in the diagnosis and determine if referral was needed. Responses were captured via a closedended survey (Qualtrics).

35 eyes of 18 patients were included. The accuracy of detecting any ocular pathology was similar between the

Ann-Marie Lobo

alobo2@uic.edu

1 Ophthalmology, University of Illinois at Chicago, Chicago, IL, USA

2 Ophthalmology, Wills Eye Hospital, Philadelphia, PA, USA

3 Biostatistics and Epidemiology, University of Illinois at Chicago School of Public Health, Chicago, IL, USA

4 Ophthalmology, Medical College of Wisconsin, Milwaukee, WI, USA

5 Center for Global Health, College of Medicine, University of Illinois at Chicago, Chicago, IL, USA
Forus and Optos images (aggregate calculation of 3 graders): sensitivity $71 \%$ vs. $77 \%(p=0.60)$; specificity $43 \%$ vs. $48 \%,(p=0.85)$. Image quality results are summarized in Table 1. There was greater sensitivity for detection of choroidal lesions for Optos compared to Forus (93 vs. $33.3 \%$ ) but similar sensitivity for uveitis (66.3 vs. $100 \%)$ and diabetic retinopathy (67 vs. $75 \%$ ).

Inter-grader agreement was moderate among graders for both Forus and Optos with kappa statistics of 0.50 and 0.40, respectively. Rate of referral for clinical exam based on images were similar among graders at 74 and $76 \%$ for Forus and Optos, respectively.

This pilot study showed similar sensitivity and specificity for detecting any pathology with the Forus camera compared to UWF imaging. Forus' overall sensitivity of $71 \%$ in detecting any ocular pathology falls within the sensitivity range of $71-97.9 \%$ [1, 2] to detect referral-requiring pathology. Referral rates for clinical examination were similar between both modalities. The Forus images were graded as good or acceptable more often than UWF images, consistent with newer fundus cameras found to provide similar image quality to their standard counterparts [3]. Forus' moderate inter-grader agreement (kappa 0.5) falls below that of other nonmydriatic cameras with good intergrader agreement (kappa 0.64-0.77) [1-4]. This difference is likely due to the variability in detecting pathology per grader.

Advantages of Forus when compared to UWF imaging include affordable cost of $\$ 8000-\$ 10,000$ [5] compared to the average fundus camera at $\$ 20,000-\$ 50,000$ [3], convenience, portability, and ease of use in allowing nonophthalmologists to capture images for viewing and grading by ophthalmologists.

Limitations of this study included its limited sample size, variability in graders, dilation of patients, pixilation of images, and field of view.

In conclusion, the Forus fundus camera demonstrates similar accuracy and reliability with UWF imaging in 
A

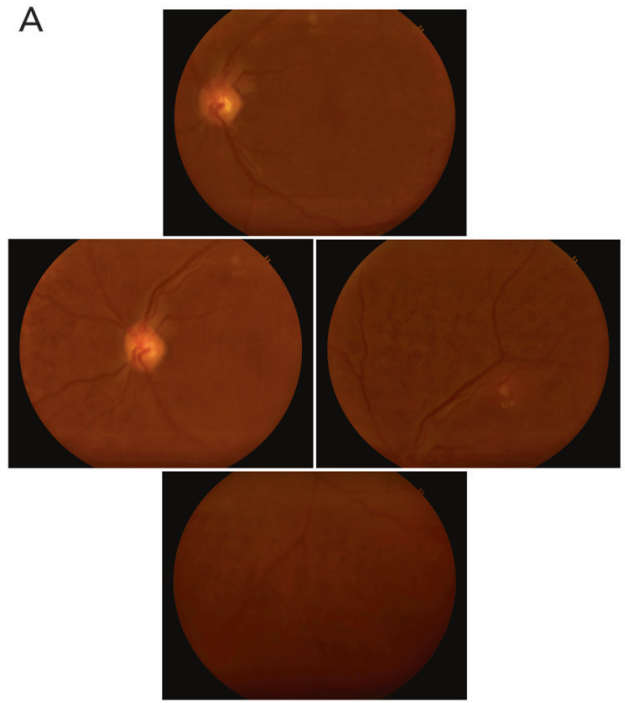

B

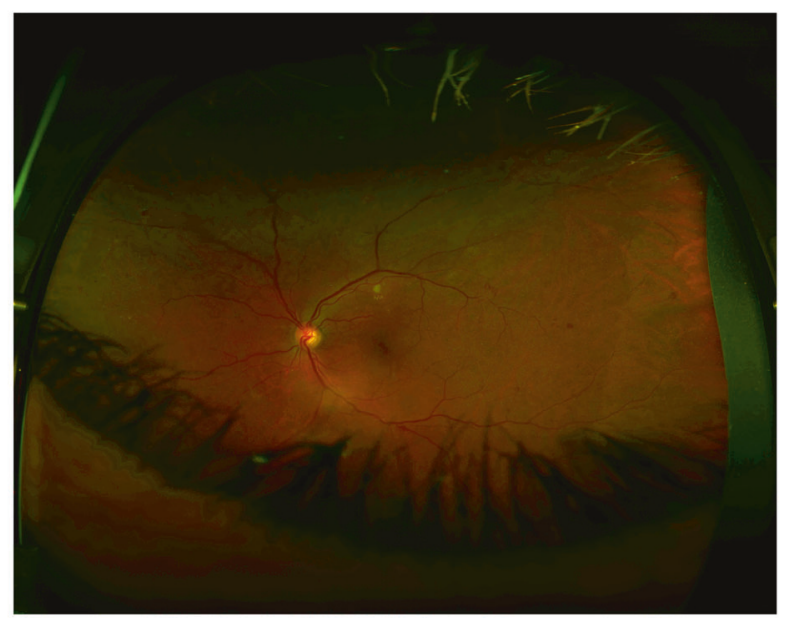

Fig. 1 Fundus images of proliferative diabetic retinopathy OS. a Forus. b Optos

Table 1 Comparison of image quality between Forus and Optos

\begin{tabular}{|c|c|c|c|c|c|c|c|c|c|c|c|}
\hline \multirow[t]{2}{*}{ Grader } & \multicolumn{2}{|c|}{ Sensitivity $(95 \% \mathrm{CI})$} & \multicolumn{2}{|c|}{ Specificity $(95 \% \mathrm{CI})$} & \multicolumn{2}{|c|}{ Good $(\%)$} & \multicolumn{2}{|c|}{ Acceptable (\%) } & \multicolumn{2}{|c|}{ Poor $(\%)$} & \multirow[t]{2}{*}{$\chi^{2} P$-values } \\
\hline & Forus & UWF & Forus & UWF & Forus & UWF & Forus & UWF & Forus & UWF & \\
\hline G1 & $\begin{array}{l}85.7 \\
(67.3,95.9)\end{array}$ & $\begin{array}{l}60.7 \\
(40.6,78.5)\end{array}$ & $\begin{array}{l}28.6 \\
(3.7,70.9)\end{array}$ & $\begin{array}{l}71.4 \\
(29.0,96.3)\end{array}$ & 14.3 & 2.9 & 40 & 34.2 & 45.7 & 62.9 & 0.152 \\
\hline G2 & $\begin{array}{l}75 \\
(55.1,89.3)\end{array}$ & $\begin{array}{l}82.1 \\
(63.1,93.9)\end{array}$ & $\begin{array}{l}57.1 \\
(18.4,90.1)\end{array}$ & $\begin{array}{l}57.1 \\
(18.4,90.1)\end{array}$ & 37.1 & 0 & 57.1 & 14.2 & 5.7 & 85.7 & $<0.0001$ \\
\hline G3 & $\begin{array}{l}53.6 \\
(33.9,72.5)\end{array}$ & $\begin{array}{l}89.3 \\
(71.8,97.7)\end{array}$ & $\begin{array}{l}42.9 \\
(9.9,81.6)\end{array}$ & $\begin{array}{l}14.3 \\
(3.6,57.9)\end{array}$ & 37.1 & 2.9 & 45.7 & 48.5 & 17.1 & 48.5 & $<0.0001$ \\
\hline
\end{tabular}

detecting ocular pathology. Further data must be collected in order to validate Forus' screening capabilities for specific ocular pathologies and use in telemedicine.

\section{Disclaimer}

The content is solely the responsibility of the authors and does not necessarily represent the official views of the NIH, NSF, or RPB. The sponsors and funding organizations had no role in the design or conduct of this research.

Acknowledgements We would like to thank the Research to Prevent Blindness, NIH, and NSF for their grant support in this pilot study.

Funding: This work was supported by grants R01 EY19474 (RVPC, KEJ); NSF SCH-1622679 (RVPC, KEJ), P30 EY001792 (AML, PB, FYC, JIL, RVPC, KEJ); NIH/NEI K12 EY021475 (AML, FYC) unrestricted departmental funding from Research to Prevent Blindness, New York, NY (AML, PB, FYC, JIL, RVPC, KEJ).

\section{Compliance with ethical standards}

Conflict of interest RVPC is a member of the Scientific Advisory Board for Visunex Medical Systems (Fremont, CA). The other authors declare that they have no conflict of interest.
Publisher's note: Springer Nature remains neutral with regard to jurisdictional claims in published maps and institutional affiliations.

\section{References}

1. Vujosevic S, Benetti E, Massignan F, et al. Screening for diabetic retinopathy: 1 and 3 nonmydriatic 45-degree digital fundus photographs vs 7 standard early treatment diabetic retinopathy study fields. Am J Ophthalmol. 2009;148:111-8.

2. Boucher MC, Gresset JA, Angioi K, Olivier S. Effectiveness and safety of screening for diabetic retinopathy with two nonmydriatic digital images compared with the seven standard stereoscopic photographic fields. Can J Ophthalmol/J Can d'Ophtalmologie. 2003;38:557-68.

3. Ryan ME, Rajalakshmi R, Prathiba V, et al. Comparison among methods of retinopathy assessment (CAMRA) study: smartphone, nonmydriatic, and mydriatic photography. Ophthalmology. 2015; 122:2038-43.

4. Neubauer AS, Kernt M, Haritoglou C, et al. Nonmydriatic screening for diabetic retinopathy by ultra-widefield scanning laser ophthalmoscopy (Optomap). Graefe's Arch Clin Exp Ophthalmol. 2008;246:229-35.

5. Forus. 3nethra. http://forushealth.com/assets/download/3nethra_Cla ssic.pdf 